\title{
Current Dimensions of Maritime Container Shipping
}

\author{
Donka Zhelyazkova \\ d_zhelyazkova@ue-varna.bg \\ University of Economics - Varna
}

\begin{abstract}
The main aim of present study is to consider the advantages and disadvantages of containers as a major transport unit in maritime transport and to outline the current dimensions of international container transport, on the basis of which to draw conclusions about their development. In order to achieve this objective, a theoretical overview of the advantages and disadvantages of containers as the main transport unit in maritime transport has been carried out, in a dynamic plan are studied data measuring the main parameters of international container transport and trends in their development have been uncovered. On this basis, conclusions are formulated regarding the development of international container transport during the observed period.
\end{abstract}

Keywords: sea transport, container shipping.

JEL Code: L90, N70, O18 DOI: https://doi.org/10.36997/IJUSV-ESS/2020.9.1.120

\section{Въведение}

Морският транспорт е един от стълбовете в икономическото развитието предвид неговото интензивно използване в международния обмен на стоки и възможностите, които той разкрива пред стопанските субекти при вземане на транспортни решения в условията на несигурност, предизвиквани от разпространението на пандемии и глобални кризисни процеси (военни конфликти, икономически кризи и др.). Неговата роля при осъществяване на превозите в световен мащаб става все по-значима и особен принос в това отношение имат контейнерните превози, които допринасят за ускоряване на движението и оптимизиране на логистичните разходи.

Целта на разработката е да бъдат разгледани предимствата и недостатъците на контейнерите като основна транспортна единица в морския транспорт и да бъдат очертани актуални измерения на международните контейнерни превози, въз основа на което да бъдат формулирани изводи относно тяхното развитие.

За постигане на така формулираната цел могат да бъдат изведени три основни задачи: 1. Да се направи теоретичен обзор на предимствата и недостатьците на контейнерите като основна транспортна единица в морския транспорт.

2. Въз основа на данни, измерващи основни параметри на международните контейнерни превози, да се проследят тенденции на динамиката в тяхното развитие.

3. Да се формулират изводи относно развитието на международните контейнерни превози през изследвания период.

\footnotetext{
1. Теоретичен обзор на предимствата и недостатыците на контейнерите като основна транспортна единица в морския транспорт

Стремежът към глобално развитие във всички сектори налага вземането на гъвкави логистични решения, които са повлияни от редица фактори, по-важните от които са (Kirova, 2013):

- Разширяването на териториалния обхват на веригите на стойността с оглед повишаването на ефективността на транспорта.

- Осигуряване на по-високо равнище на контрол над веригите за стойността, чрез намаляване на разходите за телекомуникационно обслужване и развитие на ИКТ.

- Технологичното усъвършенстване, предимно в областта на интермодалния транспорт съдейства на процеса на непрекъсваемост между различните видове транспорт, в частност сухопьтен/морски, а следователно и при продуктовите вериги.
} 
Отчитането на тези фактори допринася да се ускори придвижването на товарите, особено по суша и вода, както и да се създадат предпоставки за спазване основните принципи в логистиката, свързани с точността на доставките по отношение на място, време, качество и количество.

Особена роля в това отношение играе контейнерьт, който по дефиниция представлява „изделие от транспортно съоръжение: 1. от дълготрайно естество и съответно достатъчно здраво, подходящо за многократно използване; 2. специално проектирано, за да улесни превоза на товари с един или няколко вида транспорт, без междинно претоварване; 3. с устройства, позволяващи лесното му манипулиране, по-специално от един вид транспорт на друг; 4. така проектирано, че да бъде лесно да се напълва и изпразва; 5. с дължина 20 фута или повече“ (Reglament (EO) №425/2007, Izmenenie s Reglament (ES) 2018/974).

Икономическата обосновката от използването на контейнерите, като товарни единици, се свързва с няколко основни фактора, които оказват най-силно влияние върху ефективността от тяхното използване. Такива фактори са разстояние, брой контейнери, тяхната маса и обем, размер на държавното мито, необходимост от попълване на декларация, вид на товара, тоест да се отчете факта, дали товарът принадлежи към специална категория (особено опасни, нестандартни размери, големи). Освен това могат да възникнат разходи, свързани със съхранението, товаренето и разтоварването, както и поддръжката.

Контейнерът, като основна транспортна единица в морския транспорт, има своите предимства и недостатъци (вж. табл. 1).

Таблица 1. Предимства и недостатъци на контейнерите

\begin{tabular}{|c|c|}
\hline $\begin{array}{c}\text { Предимства } \\
\end{array}$ & $\begin{array}{c}\text { Недостатъци } \\
\end{array}$ \\
\hline $\begin{array}{l}\text { Използване на специализирани транспортни } \\
\text { средства и товаро-разтоварна техника, което } \\
\text { позволява съкращаване на времето за } \\
\text { обработка на товарите }\end{array}$ & Високи разходи за наем или придобиване. \\
\hline $\begin{array}{l}\text { Опростяване и автоматизация на процеса на } \\
\text { претоварване при осьществяване на } \\
\text { мултимодални превози. }\end{array}$ & $\begin{array}{l}\text { Прилагане на т. нар. масов принцип при } \\
\text { работа с клиенти. }\end{array}$ \\
\hline $\begin{array}{l}\text { Намаляване на риска от изгубване на товара } \\
\text { и нанасяне на щети. }\end{array}$ & $\begin{array}{l}\text { Усложняване на процеса на проследяване на } \\
\text { контейнерите. }\end{array}$ \\
\hline Съкращаване на сроковете за доставка. & $\begin{array}{lccr}\text { Затруднения } & \text { при } & \text { осигуряването } \\
\text { запълняемост с товари по целия маршрут. }\end{array}$ \\
\hline Намаляване на екологичните рискове. & $\begin{array}{l}\text { Високо равнище на специализация на } \\
\text { персонала на всички етапи на работа с } \\
\text { контейнерното оборудване. }\end{array}$ \\
\hline
\end{tabular}

Списъкът на посочените предимства може да се разшири в контекста на опциите контейнерите да бъдат подреждани един върху друг, да бъдат многократно употребявани, да бъде използвана широко изградената терминална мрежа, което е определящо за тяхната експлоатация и пр.

Използване на специализирани транспортни средства и товаро-разтоварна техника се отчита като предимство, тъй като позволява съкращаване на времето за обработка на товарите, но би могло да се тълкува и в контекста на слабите страните на контейнеризацията, предвид невъзможността да се извършат манипулациите на товарните единици без необходимото оборудване (Henstra, 2011).

Второто предимство на контейнерната транспортна единица произтича от възможността от една страна да се прилагат нови технологии при претоварната дейност, а от друга характерно за стандартните контейнери е тяхното универсалност по отношение на 
транспортирането с всички видове транспорт и преди всичко с воден, железопътен и автомобилен.

Намаляването на риска от изгубване на товара и нанасяне на щети свързваме с конструктивните особености на контейнерите, които се отличават със своята здравина и устойчивост при промени в условията на средата или както пише М. Раковска „Те са здрави, направени от стомана и пригодени за многократна употреба товарни единици..." (Rakovska, 2011).

Срокове при транспортирането на интермодалните единици, каквито са контейнерите, се отчитат като по-кратки, отколкото при използването на конвенционални транспортни единици (палети, чували, кашони и пр.), тъй като те позволяват да се товарят, разтоварват и претоварват едновременно големи обеми товари в рамките на кратки интервали от време, което зависи и от размера на контейнера (най-широко използвани са с размери 20 фута, 40 фута или 40 фута High Cube). Ако отчетем времевия фактор по цялата верига на доставки ще добием реална представа за тази силна страна на контейнерите.

Екологичните рискове произтичат главно при настъпване на злополуки с участието на контейнери, превозващи опасни товари, които „представляват вещества или предмети, чиито превоз изисква спазването на точно определени условия за начина на опаковане, товарене и разтоварване, подреждане и транспортиране. Най-често неспазването на тези условия може да доведе до частично или пълно увреждане на товара, опаковката или превозното средство, както и до тежки последствия за околната среда“" (BDZ, 2020).

В контекста на слабите страни на контейнерите като най-важна се отчитат „Високите разходи за наем или придобиване“ (приблизително 3000 евро, без ДДС, е цената на нов 20 футов стандартен контейнер ${ }^{1}$ ). Това на практика налага да се търсят варианти фирмата да организира техния транспорт по направление от крайната към отправната точка, независимо дали са празни или пълни или да търси реализация им на местния пазар. В резултат се калкулират допълни разходи и по-честата практика е контейнерите да се връщат обратно, независимо от тяхната натовареност със стоки. Тук следва да отбележим и факта, че контейнерите се отличават със сравнително дълъг експлоатационен живот, което води до условно намаляване на цената, ако я разпределим на броя извършени транспортни услуги.

Друга слаба страна на контейнерите се свързва с липсата на индивидуален подход при обслужването на клиентите, което до голяма степен произтича от стандартизацията, наложена по отношение на техните размери и предназначение. В резултат, на което операторите трудно могат да подходят гъвкаво в това отношение. Единственият възможен вариант да се удовлетворят специфични изисквания от страна на клиента е по отношение на организацията и маршрута, по който ще премине товара.

При съвременното развитие на технологиите „Усложняване на процеса на проследяване на контейнерите“ може да се отчита като все по-малко значим недостатък, тъй като тази проблем постепенно намира своето решение и контейнерите могат да бъдат проследявани в реално време на принципа 24/7 посредством интегрирани GPS и други глобални позициониращи решения.

За разлика от проследяемостта „Затрудненията при осигуряването на запълняемост с товари по целия маршрут“ остава предизвикателство пред спедиторите в морския транспорт. Тяхната най-важна задача е да аквизират стоки по цялата релация на движение на контейнера и да намират товари, независимо от неговото географско местоположение. Целта на тези мероприятия е да се оптимизира използваемостта на товарната единица, с което да се повишат приходите и да се редуцират разходите.

Проблемите в сектора, произтичащи от подготовката на персонала, са пряко свързани с правилната експлоатация на контейнерите, тяхното опазване и съхраняването на

1 По данни на Containex. Dostupen na: <http://www.containex.bg/bg/magazin/promocii/bg/20-skladovi-kontejnerihovo-ex-ctx-depots-bulgarien-lc20?tab=facts $>(09.09 .2020)$. 
количествените и качествените параметри на стоките при тяхното манипулиране и транспортиране. Това налага обучение на кадри и последващи действия за тяхното мотивиране и задържане на съответната работна позиция.

Теоретичният преглед открои основни предимства и недостатъци на морските контейнери, които трябва да се вземат под внимание при използването им в международния обмен, като се отчита влиянието им върху характеристиките на товара и икономическите параметри от осъществяването на превоза.

\section{2. Анализ на динамиката в развитието на международните контейнерни превози}

Глобалната икономика създава предпоставки за навлизане в практиката на множество от решения, които да допринесат за повишаване на икономическата ефективност на превозите на база разходи и време, ускоряване на движението по веригата от производителя до потребителя и достигане на по-високи нива на удовлетвореност както на крайните, така и на междинните клиенти. Целеполагането в тази насока предполага да се прилагат активно такива практики, които са доказали, че имат потенциал да допринесат за безусловното оптимизиране на транспортните процеси. В тази посока политиките на държавите, които имат условия за развитие на морски транспорт се концентрират върху изграждането, модернизират и поддържането на модерни пристанищни инфраструктурни решения, които да подпомогнат транслирането на материални потоци, окрупнени в контейнрни едници.

През последните години се наблюдава ръст по показателите „Производителност на контейнерните превози“ в световен мащаб. През 2019 г. световната пропускателна способност на контейнерите достигна приблизително 802 млн. еквивалентни единици от двадесет фута (TEU), което е увеличение с 2,3 \% в сравнение с предходната година, с 28,939\% спрямо 2012 г. и малко под средния ръст през изследвания период, който възлиза на 3,717 \%, при условие, че приемем прогнозните числа за 2020 г. и 2021 г., предвид конюктурните промени, които се развиват в твърде тесни времеви диапазони под влияние на пандемичната обстановка (вж. фиг. $1)$.

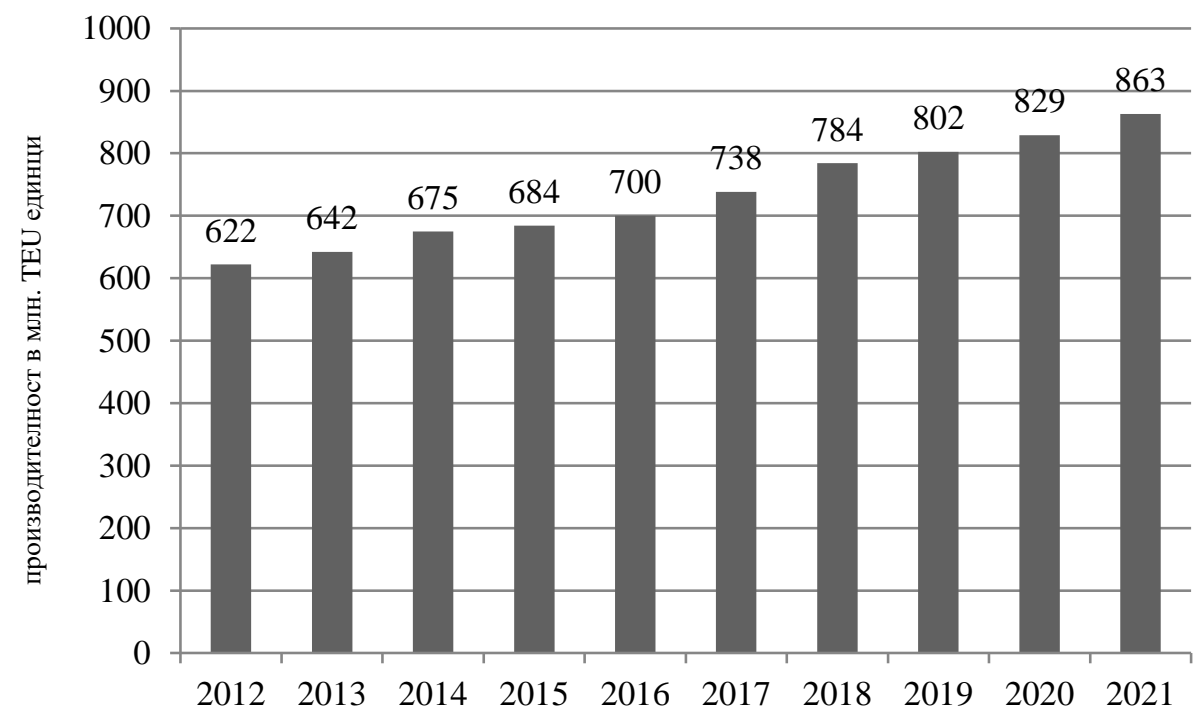

Източник: Statista (2020). Container throughput worldwide from 2012 to 2019 with a forecast for 2020 and 2021. Dostupen na: <https://www.statista.com/statistics/913398/container-throughput-worldwide/> (02.07.2020).

Фигура 1. Производителност на контейнерните превози в световен мащаб от 2012 г. до 2019 г. с прогноза за 2020 г. и 2021 г. (Container throughput worldwide from 2012 to 2019 with a forecast for 2020 and 2021)

Фактьт, че най-големите пристанища в света, обработващи контейнеризирани товари са локализирани в Азия оказа съществено влияние върху разработването на маршрути в 
условията на пандемия, но не е за пренебрегване и икономическата сила на азиатския регион, който е главен производствен център. В тази връзка следва отбележим, че коронавирусът (COVID-19) дълбоко разтърси световната икономика, под натиска на тоталното затваряне на границите и преформатиране на маршрутите.

Силно пострада от създалата се нестандартна икономическа обстановка и морската логистика, която трябваше да понесе загуби от липсата на активност на контейнеровози по целия свят. Водещите операторите на този пазар притежават 1205 собствени плавателни съдове и 1933 чартърни кораби (вж. фиг. 2).

В този сегмент на транспортния пазар конкуренцията е на сериозни равнища като забелязваме, че пьрвите четири компании притежават $62,241 \%$ от собствените кораби и $72,892 \%$ от чартьрните, което ги прави лидери на пазара и е индикация за много висока степен на концентрация в сектора, което би могло да бъде тълкувано като следствие от наложените високи глобални стандарти към тази транспортна услуга. Трябва да отчетем и факта, че до известна степен техният флот е дебалансиран в полза на чартьрните кораби, като единствено APM Maersk прави изключение, тъй като компанията разполага с 315 собствени съда и 343 чартърни.

Към 2020 г. флотът на контейнерните кораби на Maersk (Maersk, 2020) има капацитет от около четири милиона еквивалентни единици на двадесет фута (TEU). Компанията е датска и е със седалище в Копенхаген. Тя оперира на пазара от 1904 г., а към днешна дата извършва логистични и спедиционни услуги под марките: "MAERSK LINE", "DAMCO”, "Safmarine". Компания Maersk притежава повече от 50 контейнерни терминала в целия свят.

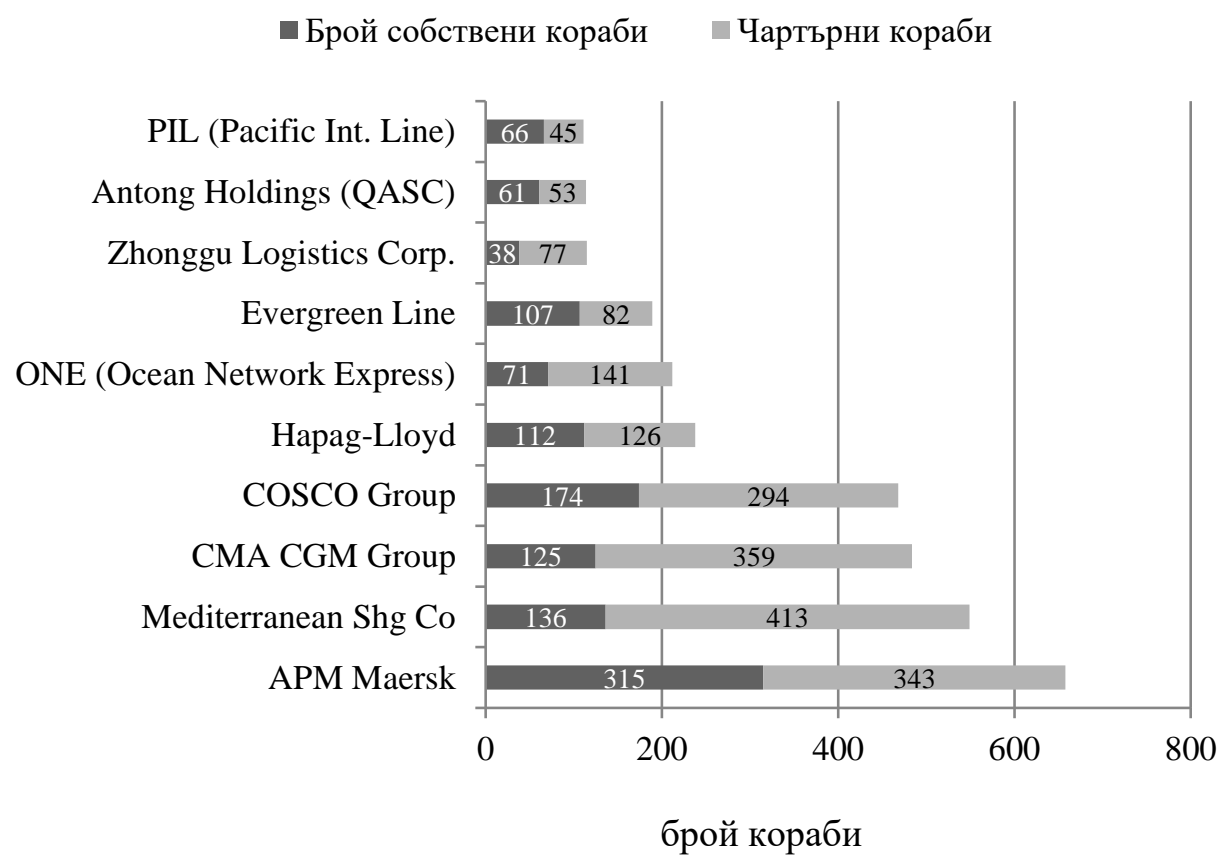

Източник: Statista (2020). The world's leading container ship operators as of June 3, 2020, based on number of owned and chartered ships. Dostupen na: <https://www.statista.com/statistics/197643/total-number-of-ships-of-worldwideleading-container-ship-operators-in-2011/> (09.09.2020).

Фигура 2. Водещи оператори на контейнерни кораби - собствени и чартьрни кораби към юни 2020 г.

В Европа терминалите са: Алджезира, Архус, Бремерхафен, Каляри, Констанца, Дюнкерк, Гданкс, Генуа, Джоя Тауро, Джейд Весер Порт във Вилхенсхавен, Калининград, Хавр, Ротердам, Зеембрюге.

В Северна Америка: Чарлстьн, Хюстьн, Джаксънвил, Кингстьн, Лос Анджелис, Маями, 
Нови Джорк, Ню Джърси, Мобил, Ню Орлиънс, Порт Елизабет, Оукланд, Портсмут, Порт Евърглейдс, Порт Савана, Такома.

В Южна Америк: Буенос Айрес, Итаджай.

В Азия: Акаба, Бахрейн, Чай Меп (Виетнам), Далиан, Гаосюн, Кобе, Лаем Чабанг (Тайланд), Бомбай, Пипавав, Порт Касим, Кингдао, Танджунг Пелепас, Салалах, Шанхай, Йокохама.

В Африка: Абиджан, Алапа, Дуала, Порт Саид, Порт Оне (Нигерия), Танжер.

Благодарение на контейнерните си терминали, компанията успява да привлече повече клиенти, а един от най-впечатляващите контейнерни кораби на Maersk e Magleby Maersk. Съдът Triple-E е построен от южнокорейската компания за корабостроене и морско инженерство Daewoo през 2014 г., която е една от най-големите корабостроителни компании в целия свят. Корабът е с капацитет от 18270 TEU, 194849 бруто тонаж, 194417 DWT.

Средиземноморска корабоплавателна компания (Mediterranean Shg Co), която е швейцарско-италианска международна морска линия, е втората по големина корабна линия в света по отношение на капацитета на контейнеровозите с общо 549 плавателни съда.

В топ 3 попада и френска компания за транспорт и превоз на контейнери CMA CGM Group, която е водеща световна група за корабоплаване, покриваща над 200 маршрута между 420 пристанища в 150 различни страни.

Основните маршрути, по които се движат карго потоци в световния океан, са три: Транс - Пасифик, Европа - Азия - Европа и Трансатлантически (вж. фиг. 3).

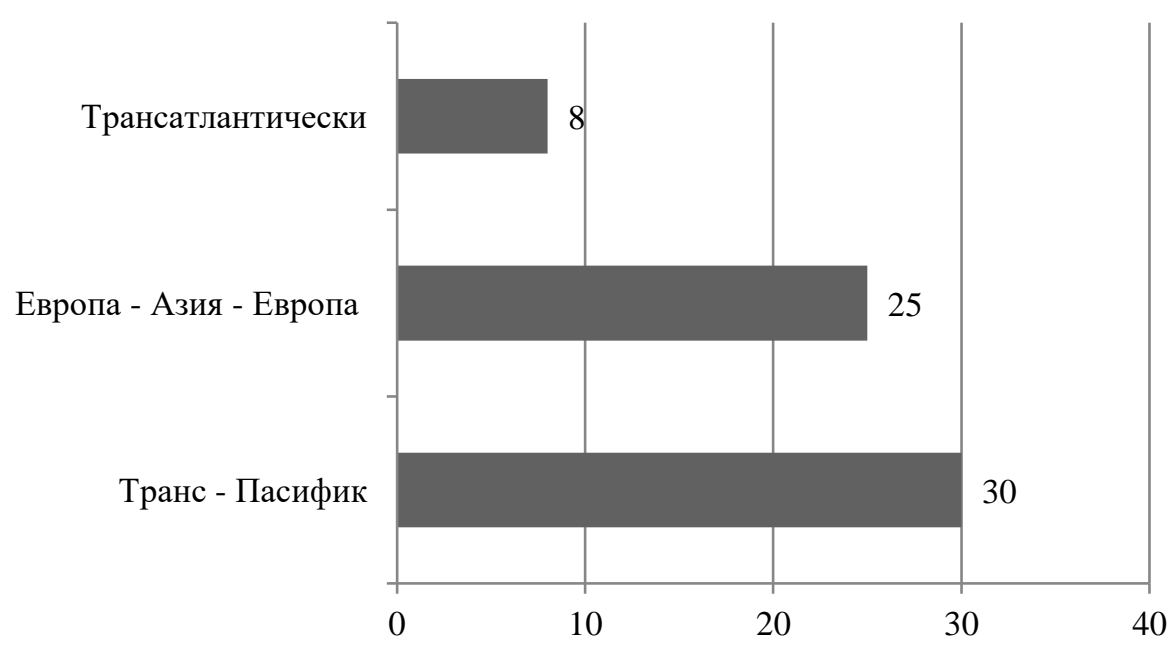

млн. TEU единици

Източник: Statista (2020). Estimated containerized cargo flows on major container trade routes in 2019, by trade route. Dostupen na: <https://www.statista.com/statistics/253988/estimated-containerized-cargo-flows-on-majorcontainer-trade-routes/> (02.09.2020).

Фигура 3. Движение на потоци от контейнеризирани товари по основните търговски маршрути през 2019 г.

По данни на международната статистика най-експлоатационно активен е маршрутьт Транс - Пасифик, по който са преминали над 30 млн. TEU през 2019 г., следван от маршрута Европа - Азия - Европа с 25 млн. TEU и на последно място е Трансатлантическият маршрут с 8 млн. TEU. Маршрутът Транс - Пасифик се открояват сред останалите транспортни варианти, тъй като този воден басейн, освен че е най-големият на Земята, той свързва и двата най-силни икономически центъра в света - Азия и Америка.

Ако разгледаме динамиката в развитието на контейнерните превози в регионален мащаб, обхващащ Черноморския басейн, ще можем да откроим мястото на двете най-големи 
български пристанища в трафика на контейнеризирани товари по море (вж. табл. 2 и фиг. 4).

Таблица 2. Контейнерен товарооборот по държави от Черноморския басейн за периода $2017-2018$ г.

\begin{tabular}{|l|r|r|r|}
\hline \multicolumn{1}{|c|}{ Държава } & 2017, TEU & 2018, TEU & Ръст,\% \\
\hline Украйна & 580754 & 691060 & 18,99 \\
\hline Русия & 543106 & 564518 & 3,94 \\
\hline Румъния & 480206 & 481877 & 0,35 \\
\hline Грузия & 229619 & 263233 & 14,64 \\
\hline България & 179363 & 187465 & 4,52 \\
\hline Общо & 2013048 & 2188153 & 8,7 \\
\hline
\end{tabular}

Източник: Port 24 (2019). Black Sea Container Market Review 2018. Dostupen na: <https://www.ports24.com/blacksea-container-terminals-handled-2-927-016-teu-in-2018/> (17.09.2020).

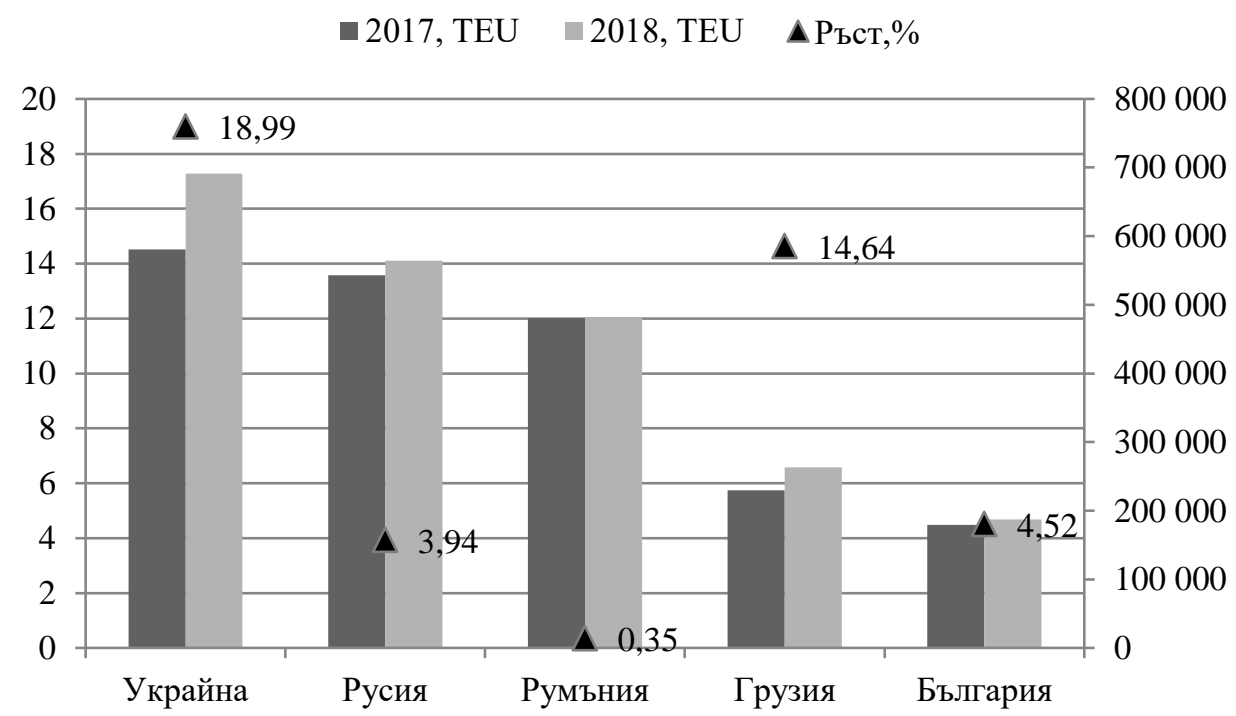

Фигура 4. Контейнерен товарооборот по държави от Черноморския басейн за периода 2017 - 2018 г.

Данните еднозначно поставят българските пристанища на последна позиция и открояват Украйна като страна с най-големи обеми на товарооборот, измерен в TEU единици и с положителна тенденция на развитие, отбелязваща ръст от приблизително $19 \%$ в рамките на една година.

Аналогично на световните пазари и в регионален мащаб се забелязва, че международни оператори като MAERSK, MSC, COSCOCS, ARKAS и ZIM контролират 71,83\% от пазара на Черно море.

Значимостта на морските превози и по-специално на контейнерните превози ще запазят своите позиции в дългосрочен план на открития фрахтов пазар, тъй като е доказано ефективен подход при транспортирането на товари, но секторът е силно засегнат от неблагоприятните условия, в които функционира световната икономика и това редуцира транспортната активност на фирмите.

\section{3. Изводи относно теоретичните постановки и развитието на международните контейнерни превози}

Въ3 основа на теоретичния обзор и проведените анализи могат да бъдат изведени следните основни изводи: 
1. В теоретичен план се откроиха някои предимства на контейнерите като основни транспортни единици в морския транспорт, които подпомагат организацията на движението на материалните потоци в международна среда, тъй като са свързани с използването на специализирани транспортни средства и товаро-разтоварна техника, което позволява съкращаване на времето за обработка на товарите; опростяване и автоматизация на процеса на претоварване при осъществяване на мултимодални превози; намаляване на риска от изгубване на товара и нанасяне на щети; съкращаване на сроковете за доставка и намаляване на екологичните рискове.

Респективно бяха систематизирани и някои недостатъци на контейнерите, които водят до завишаване на разходите, предвид нивата на наемите и цените за тяхното придобиване. Контейнеризацията свързахме и с прилагане на т. нар. масов принцип при работа с клиенти, което рефлектира негативно върху удовлетвореността на клиентите и нивата на тяхното обслужване.

2. Отчитаме формиране на възходящ тренд на развитие по показателите, измерващи производителността на контейнерните превози в световен мащаб от 2012 г. до 2019 г. с позитивна прогноза за 2020 г. и 2021 г. Следва да се постави под въпрос оптимистичната прогноза за 2020 г. и 2021 г. предвид тоталната промяна на условията, в които оперират морските превозвачи от месец март на 2020 г. и дългосрочните негативи, които кризата ще акумулира. Те категорично засягат цялата икономическа активност, а като резултат и динамиката на транспортните процеси, които отбелязват висока степен на деактивност.

3. Силно повлияни от пандемията, започнала от китайския град Ухан, са и найзначимите оператори на контейнерни кораби, сред които се откроява АРM Maersk със своите 658 кораба, от които 315 собствени и 343 чартърни. Компанията е развили своя мрежа от контейнерни пристанища, инвестира в модерни плавателни съдове, но трябва да се адаптира към условията на външната среда, които към настоящия момент са крайно неблагоприятни.

4. В рамките на Черноморския регион лидер на пазара на контейнерни превози е Украйна, следвана от Русия, Румъния и Грузия. България отчита през 2017 и 2018 г. най-малки обеми на превозени товари в TEU единици. Този факт поставя редица въпроси, свързани с модернизирането на българските пристанища, които да могат да поемат по-голям контейнерен трафик и да заемат конкурентна позиция в региона.

\section{Заключение}

Непрекъснатото разширяване на икономическите интереси на стопанските субекти и интензифицирането на движението на значителни обеми материални потоци между все поотдалечени отправни и крайни точки в условията на несигурност и риск, предизвикани от форсмажорни обстоятелства като пандемии, военни конфликти и пр., поставя морският транспорт във фокуса на вниманието, предвид неговите особености и конкурентни предимства пред останалите транспортни варианти. Основен принос за активната експлоатация на морските пространства за придвижване на товари има контейнеризацията, която разкрива широк потенциал за осъществяване на превози при оптимални икономически условия в съответствие с изискванията за редуциране на времевите параметри при обработка на товарите, максимална степен на използване на пространствата в транспортните средства и разкриване на възможности за комбинативност при вземане на транспортни решения.

Предвид обективните обстоятелства на средата много фирми избират да се възползват от контейнерните превози, което засилва позициите на операторите на този пазарен сегмент и повишава тяхната производителност в световен мащаб.

\section{Използвана литература}

1. A. P. Møller-Maersk (2020) Maersk. Dostupen na: <https://www.shiphub.co/maersk/> (12.09.2020). 
2. BDZ (2020) Opasni tovari. Dostupen na: <https://bdzcargo.bdz.bg/bg/prevoz-pod-opredelenirejimi/opasni-tovari.html> (12.07.2020).

3. Evropeřski parlament i suvet (2018) Reglament (EO) №425/2007, Izmenenie s Reglament (ES) 2018/974. Dostupen na: <https://eur-lex.europa.eu/legalcontent/BG/TXT/PDF/?uri=CELEX:02007R0425-20180805\&from=BG> (09.09.2020).

4. Henstra, D., J. Woxenius (2011) Intermodal Transport in Europe, TNO-report, Intro/log., p. 15.

5. Kirova, An. (2013) Transport, Globalizatsiya i Mezhdunarodna Turgoviya. // Mekhanika, Transport, Komunikatsii, tom 11, br. 3, s. III-38.

6. Port 24 (2019). Black Sea Container Market Review 2018. Dostupen na: <https://www.ports24.com/black-sea-container-terminals-handled-2-927-016-teu-in-2018/> (17.09.2020).

7. Rakovska, M. (2011) Mezhdunarodna logistika. Sofiya: Universitetsko izdatelstvo „Stopanstvo“, s. 242.

8. Statista (2020). The world's leading container ship operators as of June 3, 2020, based on number of owned and chartered ships. Dostupen na: <https://www.statista.com/statistics/197643/totalnumber-of-ships-of-worldwide-leading-container-ship-operators-in-2011/> (09.09.2020).

9. Statista (2020). Estimated containerized cargo flows on major container trade routes in 2019, by trade route. Dostupen na: <https://www.statista.com/statistics/253988/estimated-containerizedcargo-flows-on-major-container-trade-routes/> (02.09.2020).

10. Statista (2020). Container throughput worldwide from 2012 to 2019 with a forecast for 2020 and 2021. Dostupen na: <https://www.statista.com/statistics/913398/container-throughputworldwide/> (02.07.2020). 